\title{
Regulation by AMP-activated protein kinase of $\mathrm{PGE}_{2}$-induced osteoprotegerin synthesis in osteoblasts
}

\author{
SHINGO KAINUMA ${ }^{1,2}$, TAKANOBU OTSUKA ${ }^{1}$, GEN KUROYANAGI ${ }^{1,2}$, NAOHIRO YAMAMOTO ${ }^{1,2}$, \\ RIE MATSUSHIMA-NISHIWAKI ${ }^{2}$, OSAMU KOZAWA ${ }^{2}$ and HARUHIKO TOKUDA ${ }^{2,3}$ \\ ${ }^{1}$ Department of Orthopedic Surgery, Nagoya University Graduate School of Medical Sciences, Nagoya, Aichi 467-8601;
${ }^{2}$ Department of Pharmacology, Gifu University Graduate School of Medicine, Gifu, Gifu 501-1194;
${ }^{3}$ Department of Clinical Laboratory, National Center for Geriatrics and Gerontology, Obu, Aichi 474-8511, Japan
}

Received March 30, 2015; Accepted January 28, 2016

DOI: $10.3892 / \mathrm{mmr} .2016 .4900$

\begin{abstract}
Adenosine monophosphate-activated protein kinase (AMPK) is currently recognized to act as a key sensing enzyme in the regulation of cellular energy homeostasis. It has been previously demonstrated that prostaglandin $\mathrm{E}_{2}\left(\mathrm{PGE}_{2}\right)$ stimulates the synthesis of osteoprotegerin (OPG) through the activation of p38 mitogen-activated protein (MAP) kinase, p44/p42 MAP kinase and stress-activated protein kinase/ c-Jun N-terminal kinase (SAPK/JNK) in osteoblast-like MC3T3-E1 cells. In the present study, it was investigated whether AMPK is implicated in the $\mathrm{PGE}_{2}$-induced $\mathrm{OPG}$ synthesis in MC3T3-E1 cells. PGE $_{2}$ was observed to induce the phosphorylation of AMPK $\alpha$ (Thr-172) and AMPK $\beta$ (Ser-108) in a time-dependent manner. $\mathrm{PGE}_{2}$ additionally induced the phosphorylation of acetyl-coenzyme A (CoA) carboxylase, a direct substrate of AMPK. Compound $\mathrm{C}$, an inhibitor of AMPK, which attenuated the phosphorylation of acetyl-CoA carboxylase, significantly suppressed the $\mathrm{PGE}_{2}$-stimulated OPG release and the mRNA expression level. Compound $\mathrm{C}$ failed to affect the $\mathrm{PGE}_{2}$-stimulated phosphorylation of $\mathrm{p} 38$ MAP kinase or p44/p42 MAP kinase. On the contrary, the phosphorylation of SAPK/JNK was markedly attenuated by compound $\mathrm{C}$. The results of the current study suggest that AMPK acts as a positive regulator in $\mathrm{PGE}_{2}$-stimulated $\mathrm{OPG}$ synthesis via SAPK/JNK signaling in osteoblasts.
\end{abstract}

\section{Introduction}

Adenosine monophosphate (AMP)-activated protein kinase (AMPK) is widely recognized as a central regulator of cellular metabolism and energy homeostasis $(1,2)$. AMPK has been

Correspondence to: Dr Haruhiko Tokuda, Department of Clinical Laboratory, National Center for Geriatrics and Gerontology, 7-430 Morioka, Obu, Aichi 474-8511, Japan

E-mail: tokuda@ncgg.go.jp

Key words: prostaglandin $\mathrm{E}_{2}$, osteoprotegerin, mitogen-activated protein kinase, AMP-activated protein kinase, osteoblast discovered as an enzyme that catalyzes the phosphorylation of acetyl coenzyme A (CoA) carboxylase, which regulates lipid synthesis (2). AMPK activity is upregulated by the elevation of the AMP/adenosine triphosphate (ATP) ratio in response to various types of physiological and pathological stress, resulting in restoring cellular enzyme balance by ATP generating pathways (3). In addition, activated AMPK suppresses ATP utilizing pathways. Therefore, AMPK is currently known to regulate metabolic homeostasis throughout the body (2).

Bone metabolism is predominantly regulated by two types of functional cells, osteoblasts and osteoclasts (4). The former cells are responsible for bone formation, while the latter cells are responsible for bone resorption. Constant bone mass is maintained by bone remodeling, which comprises osteoclastic bone resorption followed by osteoblastic bone formation. Disruption to bone remodeling can result in metabolic bone disease, including osteoporosis. Concerning the association between AMPK and bone metabolism, it has been demonstrated that AMPK activation stimulates osteoblast differentiation and bone formation, resulting in increased bone mass (5). It has been previously reported that vascular endothelial growth factor synthesis induced by basic fibroblast growth factor is regulated by AMPK in osteoblast-like MC3T3-E1 cells (6). However, the precise role of AMPK in osteoblasts remains to be fully elucidated.

Osteoprotegerin (OPG) is an essential protein secreted from osteoblasts, which inhibits osteoclast activation and its differentiation, and a member of the tumor necrosis factor receptor family along with receptor activator of nuclear factor- $\kappa \mathrm{B}$ (RANK) (7). OPG binds to RANK ligand (RANKL) as a decoy receptor, and prevents RANKL from binding to RANK, resulting in the suppression of bone resorption (7). It has been demonstrated that RANKL knockout mice suffer from severe osteopetrosis (8), suggesting that RANKL is a key regulator of osteoclastogenesis. The RANK/RANKL/OPG axis is currently recognized as a major regulatory system for osteoclast formation and activity (9).

Prostaglandins (PGs) are autocrine/paracrine modulators in the bone metabolism (10). Among them, $\mathrm{PGE}_{2}$ has been recognized as an important mediator of bone remodeling (11). It has been previously reported that $\mathrm{PGE}_{2}$ stimulates $\mathrm{OPG}$ synthesis via the activation of $\mathrm{p} 38$ mitogen-activated protein 
(MAP) kinase, p44/p42 MAP kinase and stress activated protein kinase/c-Jun $\mathrm{N}$-terminal kinase (SAPK/JNK) in osteoblast-like MC3T3-E1 cells (12). However, the detailed mechanism underlying $\mathrm{PGE}_{2}$-stimulated $\mathrm{OPG}$ synthesis in osteoblasts remains to be fully elucidated.

In the present study, the involvement of AMPK in the synthesis of OPG induced by $\mathrm{PGE}_{2}$ in osteoblast-like MC3T3-E1 cells was investigated. The current study aimed to investigate whether AMPK positively regulates the $\mathrm{PGE}_{2}$-stimulated OPG synthesis via the SAPK/JNK pathway in these cells.

\section{Materials and methods}

Materials. $\mathrm{PGE}_{2}$ was obtained from Sigma-Aldrich (St. Louis, MO, USA). The mouse OPG enzyme-linked immunosorbent assay (ELISA) kit was purchased from R\&D Systems, Inc. (Minneapolis, MN, USA). Compound C was obtained from Calbiochem; EMD Millipore (Billerica, MA, USA). Polyclonal rabbit phosphorylated (p)-AMPK $\alpha$ (Thr-172; cat. no. 2531), p-AMPK $\beta$ (Ser-108; cat. no. 4181), p-acetyl-CoA carboxylase (cat. no. 3661), p38 MAP kinase (cat. no. 9212), p-p44/p42 MAP kinase (cat. no. 9101), p44/p42 MAP kinase (cat. no. 9102), SAPK/JNK (cat. no. 9252) antibodies, and monoclonal rabbit p-p38 MAPkinase (cat.no.4511) and p-SAPK/JNK (cat.no.4668) antibodies, were purchased from Cell Signaling Technology, Inc. (Danvers, MA, USA). Glyceraldehyde-3-phosphate dehydrogenase (GAPDH) antibodies (sc-25778) were obtained from Santa Cruz Biotechnology, Inc. (Santa Cruz, CA, USA). The Enhanced Chemiluminescence (ECL) Western Blotting Detection System was purchased from GE Healthcare Life Sciences (Chalfont, UK). Acrylamide monomer, Tris(hydroxymethyl)aminomethane, sodium dodecyl sulfate (SDS), dithiothreitol and glycerol were obtained from Nacalai Tesque, Inc. (Kyoto, Japan). $\mathrm{PGE}_{2}$ was dissolved in ethanol. Compound $\mathrm{C}$ was dissolved in dimethyl sulfoxide (Sigma-Aldrich). The maximum concentration of ethanol or dimethyl sulfoxide was $0.1 \%$, which did not affect either the assay for OPG or the detection of protein levels using western blot analysis.

Cell culture. Cloned osteoblast-like MC3T3-E1 cells, which were originally derived from newborn mouse calvaria (13), were maintained as described previously (14). Briefly, the cells were cultured in $\alpha$-minimum essential medium ( $\alpha$-MEM; Sigma-Aldrich) containing 10\% fetal bovine serum (FBS; Gibco; Thermo Fisher Scientific, Inc., Waltham, MA, USA) at $37^{\circ} \mathrm{C}$ in a humidified atmosphere of $5 \% \mathrm{CO}_{2} / 95 \%$ air. The cells were seeded into $35-\mathrm{mm}$ diameter dishes $\left(5 \times 10^{4}\right.$ cells/dish $)$ or $90-\mathrm{mm}$ diameter dishes $\left(2 \times 10^{5}\right.$ cells/dish) in $\alpha$-MEM containing 10\% FBS. Following culture for five days, the medium was exchanged for $\alpha$-MEM containing $0.3 \%$ FBS. The cells were then used for experiments after $48 \mathrm{~h}$.

Assay for $O P G$. The cultured cells were pretreated with $0.3,1,3$ or $10 \mu \mathrm{M}$ compound $\mathrm{C}$ for $60 \mathrm{~min}$, then stimulated with $10 \mu \mathrm{M}$ of $\mathrm{PGE}_{2}$ or vehicle in $1 \mathrm{ml} \alpha$-MEM containing $0.3 \% \mathrm{FBS}$, and were incubated for $48 \mathrm{~h}$ at $37^{\circ} \mathrm{C}$. The conditioned medium was collected, and the OPG concentration in the medium was measured using the mouse OPG ELISA kit according to the manufacturer's protocol.
Western blot analysis. The cultured cells were pretreated with 1,3 or $10 \mu \mathrm{M}$ compound $\mathrm{C}$ for $60 \mathrm{~min}$, and then were stimulated with $10 \mu \mathrm{M} \mathrm{PGE}_{2}$ or vehicle for $1,3,5,10$, 20,30 or $60 \mathrm{~min}$. The cells were then washed twice with phosphate-buffered saline (Sigma-Aldrich) and then lysed, homogenized and sonicated $900 \mu 1$ lysis buffer containing $62.5 \mathrm{mM}$ Tris/ $\mathrm{HCl}, \mathrm{pH}$ 6.8, 2\% SDS, $50 \mathrm{mM}$ dithiothreitol and $10 \%$ glycerol. SDS-polyacrylamide gel electrophoresis was performed by the method described by Laemmli (15) in $10 \%$ polyacrylamide gels. The protein was fractionated and transferred onto an Immun-Blot polyvinylidene difluoride (PVDF) membrane (Bio-Rad Laboratories, Inc., Hercules, CA, USA). Western blot analysis was performed as described previously (16) using p-AMPK $\alpha$ (Thr-172), p-AMPK $\beta$ (Ser-108), p-acetyl-CoA carboxylase, p-p38 MAP kinase, p38 MAP kinase, p-p44/p42 MAP kinase, p44/p42 MAP kinase, p-SAPK/JNK, SAPK/JNK and GAPDH antibodies as the primary antibodies at a dilution of 1:1,000 in $5 \%$ milk in Tris-buffered saline $(20 \mathrm{mM}$ Tris $/ \mathrm{HCl}, \mathrm{pH} 7.6$, $137 \mathrm{mM} \mathrm{NaCl}$ ) with $0.1 \%$ Tween-20 (TBST) overnight at $4^{\circ} \mathrm{C}$. Goat-anti rabbit $\operatorname{IgG}$ horseradish peroxidase-labeled antibodies (074-1506; KPL, Inc., Gaithersburg, MD, USA) were used as the secondary antibodies at a dilution of 1:1.000 in 5\% milk in TBST for $1 \mathrm{~h}$ at room temperature. Peroxidase activity on the PVDF membrane was visualized on X-ray film (Super RX; Fujifilm, Tokyo, Japan) by means of the ECL Western Blotting Detection System.

Reverse transcription-quantitative polymerase chain reaction $(R T-q P C R)$. The cultured cells were pretreated with $10 \mu \mathrm{M}$ compound $\mathrm{C}$ or vehicle for $60 \mathrm{~min}$, then were stimulated by $10 \mu \mathrm{M} \mathrm{PGE}_{2}$ or vehicle in $\alpha$-MEM containing $0.3 \%$ FBS for $3 \mathrm{~h}$. Total RNA was isolated and reverse transcribed into complementary DNA using TRIzol reagent (Invitrogen; Thermo Fisher Scientific, Inc.) and the Omniscript Reverse Transcriptase kit (Qiagen Inc., Valencia, CA, USA), respectively. RT-qPCR was performed using a LightCycler system (version 2.0; Roche Diagnostics, Basel, Switzerland) in capillaries with the FastStart DNA Master SYBR Green I provided with the RightCycler FastStart DNA kit (Roche Diagnostics). Sense and antisense primers for mouse OPG or GAPDH mRNA were purchased from Takara Bio, Inc. (Otsu, Japan; primer set ID, MA026526). Amplification of the correct PCR products was confirmed by melting curve analysis according to the manufacturer's instructions. The OPG mRNA levels were normalized to those of GAPDH mRNA.

Densitometric analysis. A densitometric analysis of the protein expression was performed using a scanner (GT-F600; Seiko Epson Corporation, Nagano, Japan) and an ImageJ analysis software, version 1.48 (National Institutes of Health, Bethesda, MD, USA). The background-subtracted signal intensity of each phosphorylation signal was normalized to the respective total protein signal and plotted as the fold increase in comparison to control cells without stimulation.

Statistical analysis. The data were analyzed by an analysis of variance, followed by the Bonferroni method for multiple comparisons between pairs. $\mathrm{P}<0.05$ was considered to indicate a statistically significant difference. All data are presented as 

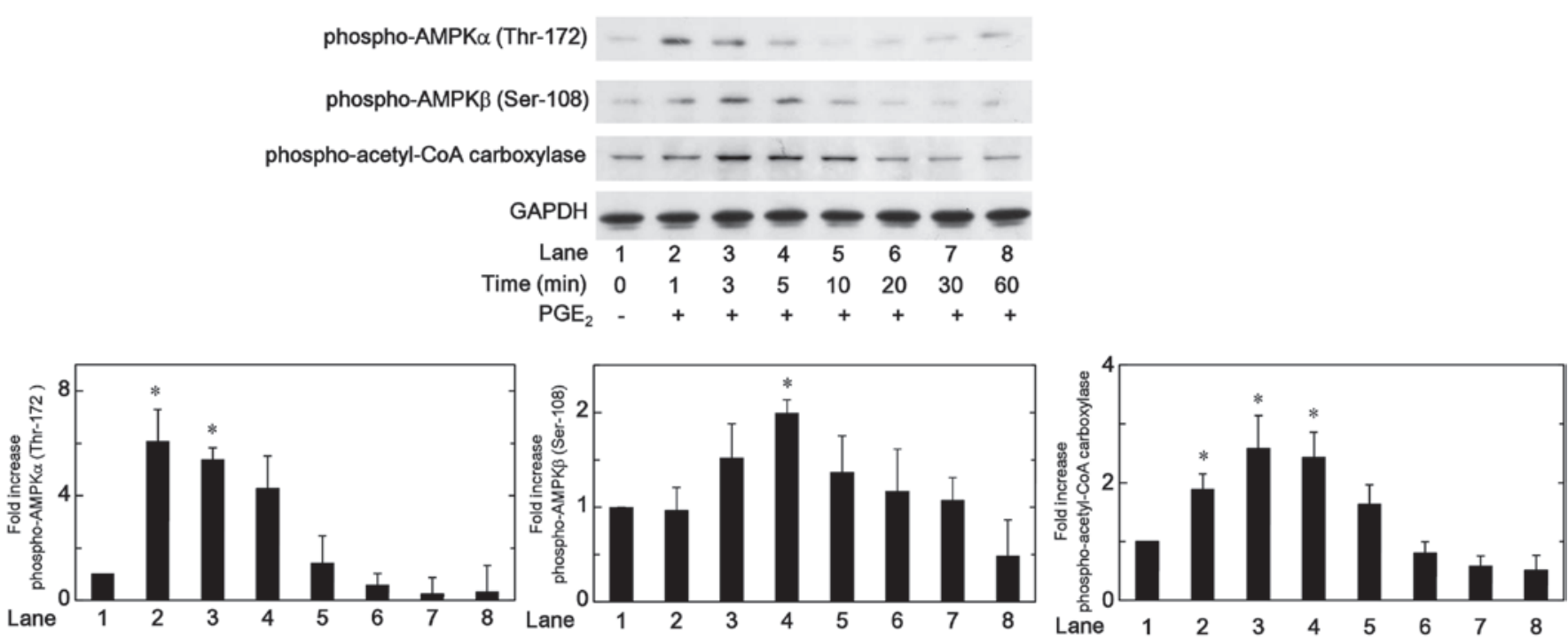

Figure 1. Effects of $\mathrm{PGE}_{2}$ on the phosphorylation of AMPK or acetyl-CoA carboxylase in MC3T3-E1 cells. The cultured cells were stimulated by $10 \mu \mathrm{M}$ of $\mathrm{PGE}_{2}$ for the indicated periods. The extracts of cells were subjected to sodium dodecyl sulfate-polyacrylimide gel electrophoresis with subsequent western blotting using antibodies against phospho-specific AMPK $\alpha$ (Thr-172), phospho-specific AMPK $\beta$ (Ser-108), phospho-specific acetyl-CoA carboxylase or GAPDH. The histograms present quantification of the levels of the PGE $_{2}$-induced phosphorylation obtained from laser densitometric analysis of three independent experiments. The phosphorylation levels were normalized to the GAPDH levels and expressed as the fold increase to the basal levels presented in lane 1. Each value represents the mean \pm standard error of triplicate determinations from three independent cell preparations. ${ }^{*} \mathrm{P}<0.05$ vs. control. $\mathrm{PGE} \mathrm{E}_{2}$, prostaglandin $\mathrm{E}_{2}$; AMPK, adenosine monophosphate-activated protein kinase; CoA, coenzyme A; phospho, phosphorylated; GAPDH, glyceraldehyde 3-phosphate dehydrogenase.

the mean \pm standard error of triplicate determinations from three independent cell preparations.

\section{Results}

Effects of $P E_{2}$ on the phosphorylation of AMPKoracetyl-CoA carboxylase in MC3T3-E1 cells. It has been previously established that the phosphorylation of AMPK is essential for its activation (17). Therefore, in order to clarify whether AMPK is activated by $\mathrm{PGE}_{2}$ in osteoblast-like MC3T3-E1 cells, the effect of $\mathrm{PGE}_{2}$ on the phosphorylation of AMPK was investigated by western blot analysis. $\mathrm{PGE}_{2}$ was observed to significantly induce the phosphorylation of AMPK $\alpha$ (Thr-172) and AMPK $\beta$ (Ser-108). The effects of $\mathrm{PGE}_{2}$ on the phosphorylation of AMPK $\alpha$ and AMPK $\beta$ reached their peak 1 min and 5 min subsequent to the stimulation, respectively, and reduced thereafter (Fig. 1). It is widely accepted that AMPK induces the phosphorylation of acetyl-CoA carboxylase as a direct substrate of AMPK, and regulates it (2). Thus, the effect of $\mathrm{PGE}_{2}$ on the phosphorylation of acetyl-CoA carboxylase was investigated in MC3T3-E1 cells. $\mathrm{PGE}_{2}$ significantly induced the phosphorylation of acetyl-CoA carboxylase, and the effect on the phosphorylation reached its peak 5 min subsequent to stimulation (Fig. 1).

Effect of compound $C$ on the $P G E_{2}$-stimulated $O P G$ release in MC3T3-E1 cells. It has been previously reported that $\mathrm{PGE}_{2}$ stimulates OPG synthesis via the activation of p38 MAP kinase, p44/p42 MAP kinase and SAPK/JNK in osteoblast-like MC3T3-E1 cells (12). In order to elucidate whether AMPK serves a role in the $\mathrm{PGE}_{2}$-induced synthesis of OPG in MC3T3-E1 cells, the effect of compound $\mathrm{C}$, an inhibitor of AMPK (18), on the release of OPG induced by

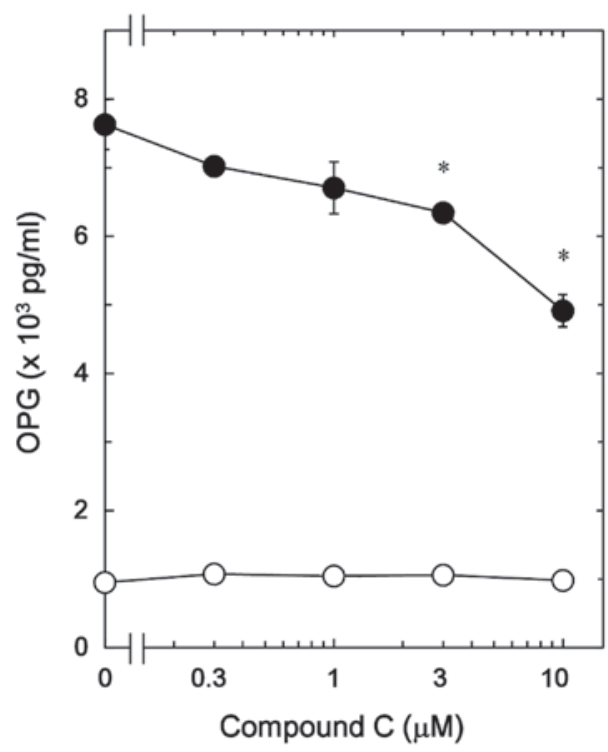

Figure 2. Effect of compound $\mathrm{C}$ on the $\mathrm{PGE}_{2}$-stimulated $\mathrm{OPG}$ release in MC3TC-E1 cells. The cultured cells were pretreated with various concentrations of compound $\mathrm{C}$ for $60 \mathrm{~min}$, and then stimulated by $10 \mu \mathrm{M}$ of $\mathrm{PGE}_{2}$ $(\bullet)$ or vehicle (०) for $48 \mathrm{~h}$. The OPG concentrations of the culture medium were determined by the enzyme-linked immunosorbent assay. Each value is presented as the mean \pm standard error of triplicate determinations from three independent cell preparations. ${ }^{*} \mathrm{P}<0.05$ vs. $\mathrm{PGE}_{2}$ alone. $\mathrm{PGE}_{2}$, prostaglandin $\mathrm{E}_{2}$; OPG, osteoprotegerin.

$\mathrm{PGE}_{2}$ was investigated. Compound $\mathrm{C}$, which by itself had minimal effect on the levels of OPG, significantly reduced the $\mathrm{PGE}_{2}$-stimulated OPG release in a dose-dependent manner in the range between 0.3 and $10 \mu \mathrm{M}$ (Fig. 2). A $10 \mu \mathrm{M}$ dose of compound $\mathrm{C}$ resulted in an approximately $40 \%$ inhibition in the $\mathrm{PGE}_{2}$-effect. 

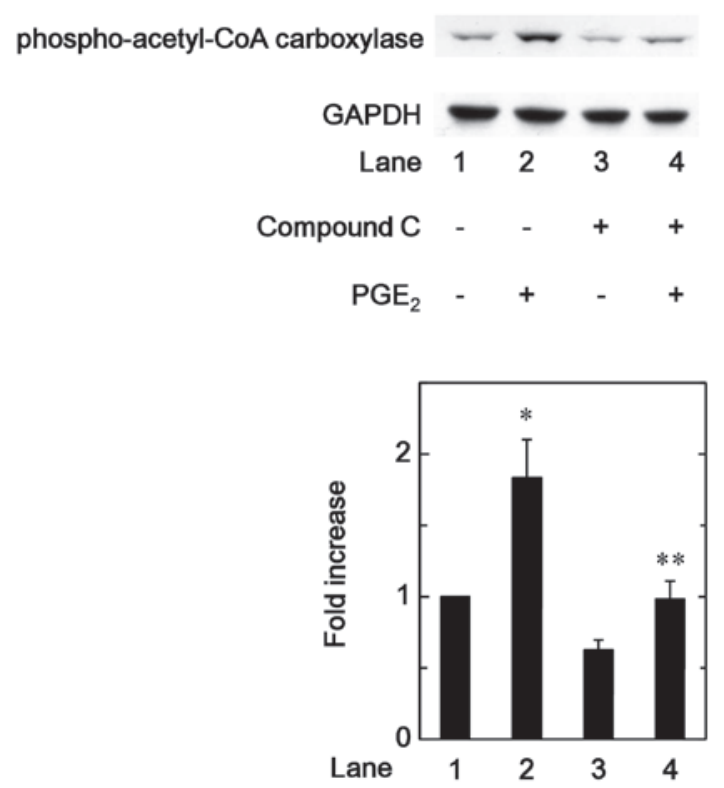

Figure 3. Effect of compound $\mathrm{C}$ on the $\mathrm{PGE}_{2}$-stimulated phosphorylation of acetyl-CoA carboxylase in MC3T3-E1 cells. The cultured cells were pretreated with $10 \mu \mathrm{M}$ compound $\mathrm{C}$ or vehicle for $60 \mathrm{~min}$, then were stimulated by $10 \mu \mathrm{M} \mathrm{PGE}_{2}$ or vehicle for $5 \mathrm{~min}$. The extracts of cells were subjected to sodium dodecyl sulfate-polyacrylamide gel electrophoresis with subsequent western blot analysis using antibodies against phospho-specific acetyl-CoA carboxylase or GAPDH. The histogram presents quantification of the levels of the $\mathrm{PGE}_{2}$-induced phosphorylation obtained from laser densitometric analysis of three independent experiments. The phosphorylation levels were normalized to GAPDH levels and expressed as the fold increase vs. basal levels presented in lane 1 . Values are presented as the mean \pm standard error of triplicate determinations from three independent cell preparations. ${ }^{*} \mathrm{P}<0.05$ vs. control; ${ }^{* *} \mathrm{P}<0.05$ vs. $\mathrm{PGE}_{2}$ alone. $\mathrm{PGE}_{2}$, prostaglandin $\mathrm{E}_{2}$; CoA, coenzyme A; phospho, phosphorylated; GAPDH, glyceraldehyde 3-phosphate dehydrogenase.

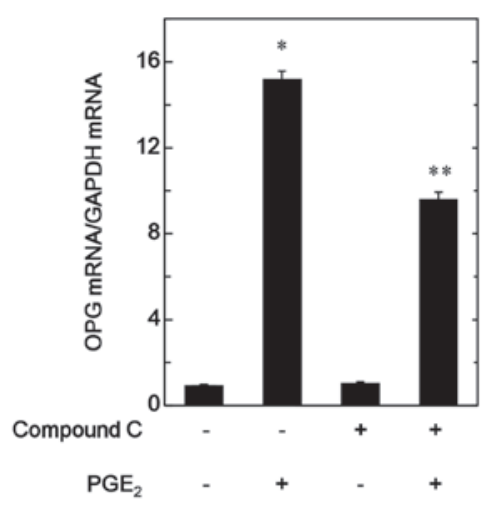

Figure 4. Effect of compound $\mathrm{C}$ on the $\mathrm{PGE}_{2}$-induced $\mathrm{OPG}$ mRNA expression in MC3T3-E1 cells. The cultured cells were pretreated with $10 \mu \mathrm{M}$ compound $\mathrm{C}$ or vehicle for $60 \mathrm{~min}$, then were stimulated by $10 \mu \mathrm{M} \mathrm{PGE}_{2}$ or vehicle for $3 \mathrm{~h}$. The respective total RNA was then isolated and quantified by reverse transcription-quantitative polymerase chain reaction. Values are presented as the mean \pm standard error of triplicate determinations from three independent cell preparations. ${ }^{*} \mathrm{P}<0.05$ vs. control; ${ }^{* *} \mathrm{P}<0.05$ vs. $\mathrm{PGE}_{2}$ alone. $\mathrm{PGE}_{2}$, prostaglandin $\mathrm{E}_{2} ; \mathrm{OPG}$, osteoprotegerin; GAPDH, glyceraldehyde 3-phosphate dehydrogenase.

Effect of compound $C$ on the $P G E_{2}$-stimulated phosphorylation of acetyl-CoA carboxylase in MC3T3-E1 cells. In order to investigate whether compound $\mathrm{C}$ functions as an
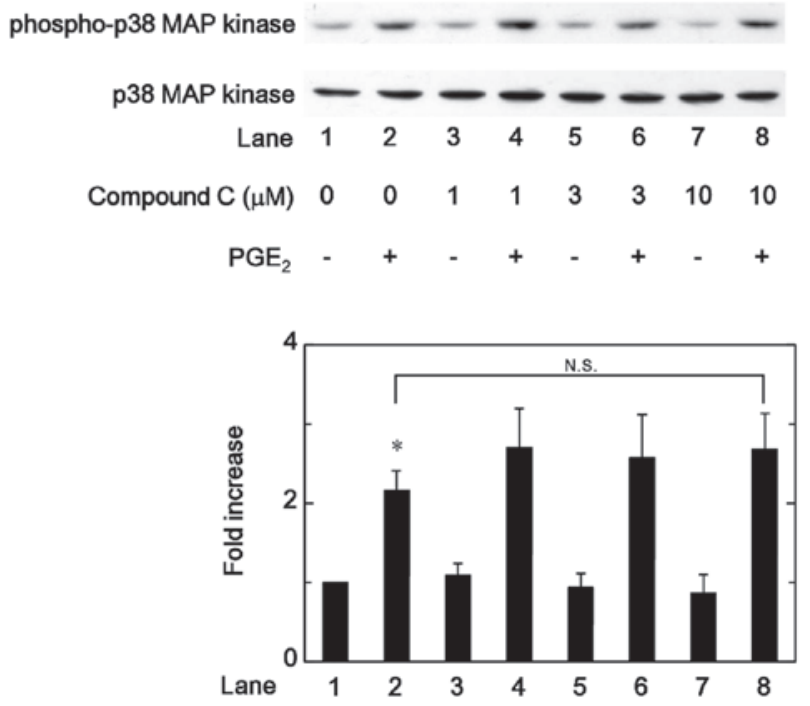

Figure 5. Effect of compound $\mathrm{C}$ on the $\mathrm{PGE}_{2}$-stimulated phosphorylation of p38 MAP kinase in MC3T3-E1 cells. The cultured cells were pretreated with various concentrations of compound $\mathrm{C}$ for $60 \mathrm{~min}$, then were stimulated by $10 \mu \mathrm{M} \mathrm{PGE}_{2}$ or vehicle for $3 \mathrm{~min}$. The cell extracts were subjected to sodium dodecyl sulfate-polyacrylamide gel electrophoresis with subsequent western blot analysis using antibodies against phospho-specific p38 MAP kinase or p38 MAP kinase. The histogram presents quantification of the levels of the $\mathrm{PGE}_{2}$-induced phosphorylation obtained from laser densitometric analysis of three independent experiments. The phosphorylation levels were corrected by the p38 MAP kinase levels and expressed as the fold increase compared with the basal levels presented in lane 1 . Values are presented as the mean \pm standard error of triplicate determinations from three independent cell preparations. ${ }^{*} \mathrm{P}<0.05$ vs. control. $\mathrm{PGE}_{2}$, prostaglandin $\mathrm{E}_{2}$; MAP, mitogen-activated protein; phospho, phosphorylated; N.S., non-significant.

inhibitor of AMPK in osteoblast-like MC3T3-E1 cells, the effect of compound $\mathrm{C}$ on the $\mathrm{PGE}_{2}$-induced phosphorylation of acetyl-CoA carboxylase was examined. Compound C significantly suppressed the $\mathrm{PGE}_{2}$-induced phosphorylation of acetyl-CoA carboxylase (Fig. 3).

Effect of compound $C$ on the PGE $E_{2}$-induced $O P G m R N A$ expression in MC3T3-E1 cells. In order to elucidate whether the suppression of the $\mathrm{PGE}_{2}$-stimulated $\mathrm{OPG}$ synthesis by compound $\mathrm{C}$ is mediated via transcriptional events in MC3T3-E1 cells, the effect of compound $\mathrm{C}$ on the $\mathrm{PGE}_{2}$-induced expression levels of OPG mRNA were investigated. Compound $\mathrm{C}$ was observed to significantly reduce the $\mathrm{PGE}_{2}$-induced OPG mRNA expression (Fig. 4).

Effects of compound $C$ on the $P G E_{2}$-stimulated phosphorylation of $p 38$ MAP kinase, $p 44 / p 42$ MAP kinase or SAPK/JNK in MC3T3-E1 cells. Regarding the intracellular signaling of $\mathrm{PGE}_{2}$ in osteoblasts, it has been previously demonstrated that $\mathrm{PGE}_{2}$ induces the activation of $\mathrm{p} 38$ MAP kinase, $\mathrm{p} 44 / \mathrm{p} 42 \mathrm{MAP}$ kinase and SAPK/JNK in osteoblast-like MC3T3-E1 cells, and that these MAP kinases function as positive regulators in the $\mathrm{PGE}_{2}$-stimulated OPG synthesis in these cells (12). Therefore, the association between AMPK and these MAP kinases in the $\mathrm{PGE}_{2}$-stimulated $\mathrm{OPG}$ synthesis was investigated in MC3T3-E1 cells. Firstly the effects of compound $\mathrm{C}$ on the $\mathrm{PGE}_{2}$-induced phosphorylation of $\mathrm{p} 38 \mathrm{MAP}$ kinase or p44/p42 MAP kinase were examined. However, compound C 

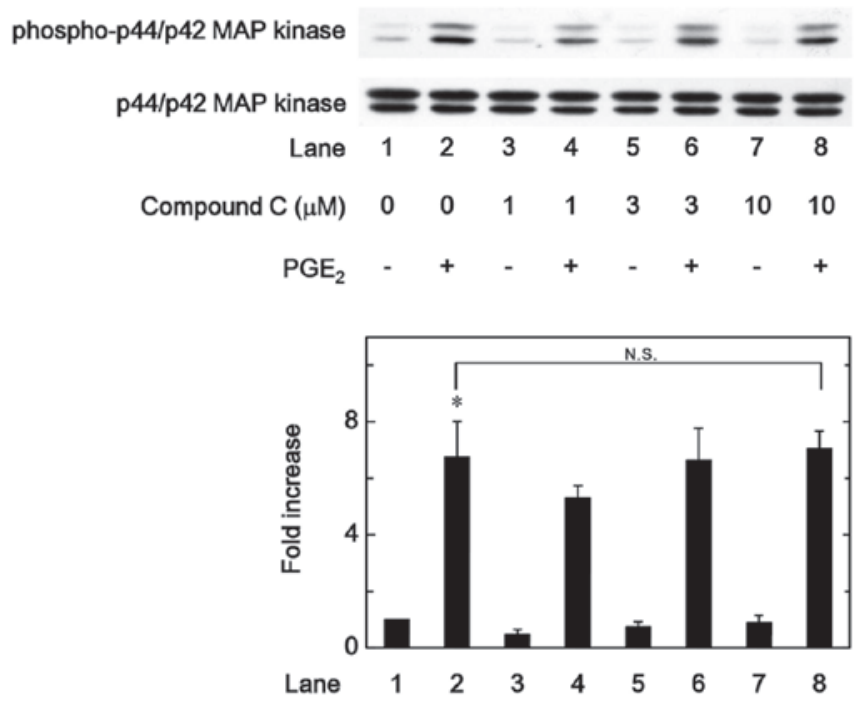

Figure 6. Effect of compound $\mathrm{C}$ on the $\mathrm{PGE}_{2}$-stimulated phosphorylation of p44/p42 MAP kinase in MC3T3-E1 cells. The cultured cells were pretreated with various concentrations of compound $\mathrm{C}$ for $60 \mathrm{~min}$, then were stimulated by $10 \mu \mathrm{M} \mathrm{PGE}_{2}$ or vehicle for $10 \mathrm{~min}$. The cell extracts were then subjected to sodium dodecyl sulfate-polyacrylamide gel electrophoresis with subsequent western blotting using antibodies against phospho-specific p44/p42 MAP kinase or $\mathrm{p} 44 / \mathrm{p} 42$ MAP kinase. The histogram presents quantification of the levels of the $\mathrm{PGE}_{2}$-induced phosphorylation obtained from laser densitometric analysis of three independent experiments. The phosphorylation levels were corrected by the p44/p42 MAP kinase levels and expressed as the fold increase compared with the basal levels presented in lane 1. Values are presented as the mean \pm standard error of triplicate determinations from three independent cell preparations. ${ }^{*} \mathrm{P}<0.05$ vs. control. $\mathrm{PGE}_{2}$, prostaglandin $\mathrm{E}_{2}$; MAP, mitogen-activated protein; phospho, phosphorylated; N.S., non-significant.
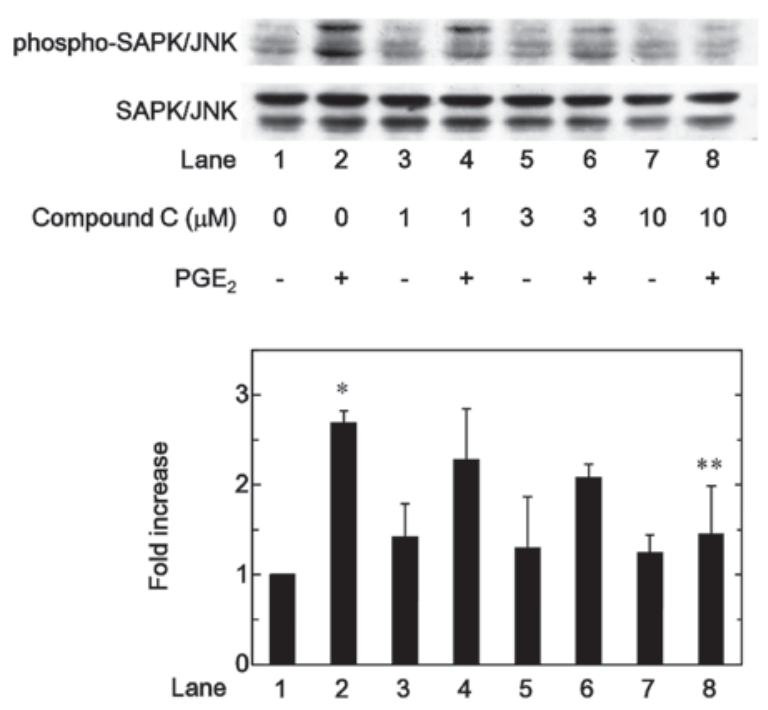

Figure 7. Effect of compound $\mathrm{C}$ on the $\mathrm{PGE}_{2}$-stimulated phosphorylation of SAPK/JNK in MC3T3-E1 cells. Cultured cells were pretreated with various concentrations of compound $\mathrm{C}$ for $60 \mathrm{~min}$, and then stimulated by $10 \mu \mathrm{M}$ of $\mathrm{PGE}_{2}$ or vehicle for $20 \mathrm{~min}$. Cell extracts were subjected to sodium dodecyl sulfate-polyacrylamide gel electrophoresis with subsequent western blotting using antibodies against phospho-specific SAPK/JNK or SAPK/JNK. The histogram presents quantification of the levels of the $\mathrm{PGE}_{2}$-induced phosphorylation obtained from laser densitometric analysis of three independent experiments. Phosphorylation levels were corrected by the SAPK/JNK levels and expressed as the fold increase compared with the basal levels presented in lane 1. Values are presented as the mean \pm standard error of triplicate determinations from three independent cell preparations. ${ }^{*} \mathrm{P}<0.05$ vs. control; ${ }^{* *} \mathrm{P}<0.05$ vs. $\mathrm{PGE}_{2}$ alone. $\mathrm{PGE}_{2}$, prostaglandin $\mathrm{E}_{2} ; \mathrm{SAPK}$, stress-activated protein kinase/c-Jun $\mathrm{N}$-terminal kinase; phospho, phosphorylated.

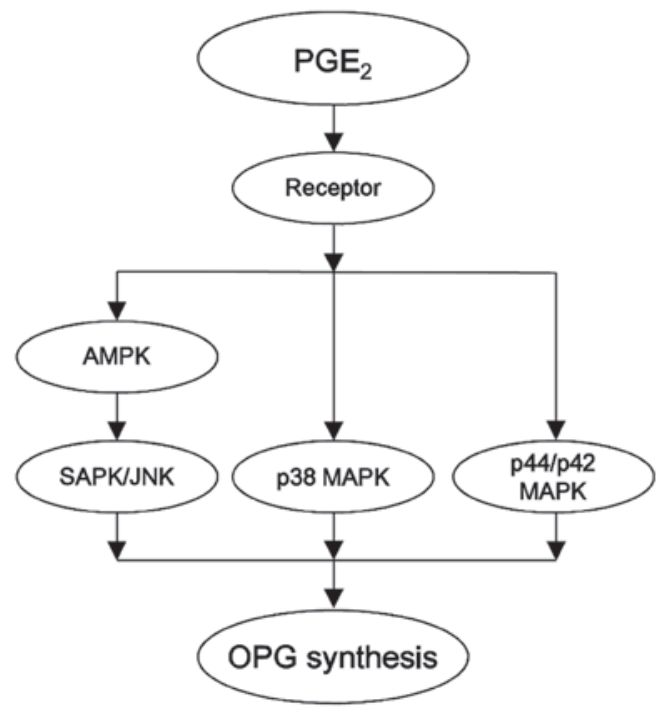

Figure 8. Schematic illustration of the involvement of AMPK in the mechanism of $\mathrm{PGE}_{2}$-stimulated $\mathrm{OPG}$ synthesis in osteoblasts. AMPK, adenosine monophosphate-activated protein kinase; $\mathrm{PGE}_{2}$, prostaglandin $\mathrm{E}_{2}$; OPG, osteoprotegerin; SAPK/JNK, stress-activated protein kinase/c-Jun N-terminal kinase; MAPK, mitogen-activated protein kinase.

was not observed to affect the $\mathrm{PGE}_{2}$-induced phosphorylation of p38 MAP kinase or p44/p42 MAP kinase in the range between 1 and $10 \mu \mathrm{M}$ (Figs. 5 and 6). By contrast, compound $\mathrm{C}$ significantly attenuated the phosphorylation of SAPK/JNK induced by $\mathrm{PGE}_{2}$ in a dose-dependent manner in the range between 1 and $10 \mu \mathrm{M}$ (Fig. 7).

\section{Discussion}

In the present study, it was demonstrated that the phosphorylation of AMPK $\alpha$ (Thr-172) and AMPK $\beta$ (Ser-108) was markedly induced by $\mathrm{PGE}_{2}$ in osteoblast-like MC3T3-E1 cells. AMPK exists as a heterotrimeric complex consisting of three subunits, which are designated $\alpha, \beta$ and $\gamma(1)$. Among the three AMPK subunits, the $\alpha$-subunit is recognized as a catalytic site, whereas the $\beta$ - and $\gamma$-subunits are regulatory sites (17). It is currently recognized that the phosphorylation of the $\alpha$-subunit is essential for AMPK activation, while the phosphorylation of the $\beta$-subunit is required for correct activation of AMPK (17). In the current study, it was demonstrated that $\mathrm{PGE}_{2}$ significantly stimulated the phosphorylation of acetyl-CoA carboxylase, a direct substrate of AMPK, in MC3T3-E1 cells. The time course of $\mathrm{PGE}_{2}$-induced AMPK $\alpha$ phosphorylation was more rapid than that of acetyl-CoA carboxylase phosphorylation. Based on these observations, it is suggested that $\mathrm{PGE}_{2}$ induces AMPK activation in osteoblast-like MC3T3-E1 cells.

In a previous study (12), it was reported that $\mathrm{PGE}_{2}$ stimulates OPG synthesis in osteoblast-like MC3T3-E1 cells. In the present study, the involvement of AMPK in the $\mathrm{PGE}_{2}$-stimulated OPG synthesis in MC3T3-E1 cells was investigated, and it was demonstrated that compound C, an inhibitor of AMPK (18), reduced the release of OPG induced by $\mathrm{PGE}_{2}$. It was additionally observed that compound $\mathrm{C}$ significantly attenuated the phosphorylation of acetyl-CoA carboxylase stimulated by $\mathrm{PGE}_{2}$. Therefore, the observations of the current study suggest that $\mathrm{PGE}_{2}$-activated $\mathrm{AMPK}$ acts as a positive regulator in $\mathrm{OPG}$ 
release. Furthermore, it was demonstrated that compound $\mathrm{C}$ significantly reduced the $\mathrm{PGE}_{2}-\mathrm{mRNA}$ expression levels of OPG. Taking these observations into account, it is suggested that $\mathrm{PGE}_{2}$ stimulates the synthesis of OPG, at least in part, via AMPK activation in osteoblast-like MC3T3-E1 cells.

It is widely accepted that the MAP kinase superfamily serves a central role in a variety of cellular functions, including proliferation, differentiation and survival (19). Three major MAP kinases, p38 MAP kinase, p44/p42 MAP kinase and SAPK/JNK, are recognized as central elements used by mammalian cells to transduce diverse types of messages (20). Regarding the signaling mechanism of the $\mathrm{PGE}_{2}$-stimulated OPG synthesis in osteoblasts, it has been previously demonstrated that $\mathrm{PGE}_{2}$ stimulates the activation of p38 MAP kinase, p44/p42 MAP kinase and SAPK/JNK in osteoblast-like MC3T3-E1 cells, and that three MAP kinases are implicated in the $\mathrm{PGE}_{2}$-stimulated OPG synthesis (12). In order to establish how AMPK functions in $\mathrm{PGE}_{2}$-stimulated OPG synthesis in MC3T3-E1 cells, the association between AMPK and three MAP kinases was investigated in the current study. It was demonstrated that compound $\mathrm{C}$ suppressed the $\mathrm{PGE}_{2}$-induced phosphorylation of SAPK/JNK without affecting the phosphorylation of p38 MAP kinase or p44/p42 MAP kinase. Based on the observations of the present study, it is suggested that $\mathrm{PGE}_{2}$ induces the activation of $\mathrm{SAPK} / \mathrm{JNK}$ via AMPK in osteoblast-like MC3T3-E1 cells. In the present study, it was demonstrated that the maximum effect of $\mathrm{PGE}_{2}$ on AMPK $\alpha$ phosphorylation was observed at 1 min subsequent to stimulation. By contrast, a previously study demonstrated that $\mathrm{PGE}_{2}$-induced SAPK/JNK phosphorylation reached its peak at $20 \mathrm{~min}$ subsequent to stimulation (12). The time course of the $\mathrm{PGE}_{2}$-induced AMPK phosphorylation appears to be more rapid than that of SAPK/JNK phosphorylation, suggesting that the $\mathrm{PGE}_{2}$-induced activation of SAPK/JNK occurs subsequent to AMPK activation. Taking the current and previous studies into account, it is suggested that AMPK acts upstream of SAPK/JNK and positively regulates the $\mathrm{PGE}_{2}$-stimulated OPG synthesis in osteoblast-like MC3T3-E1 cells. The potential mechanism of AMPK in $\mathrm{PGE}_{2}$-induced OPG synthesis in osteoblasts investigated here is summarized in Fig. 8.

AMPK is generally recognized as a key sensor in cellular energy homeostasis (1). Regarding AMPK in osteoblasts, it has been demonstrated that metformin, an activator of AMPK, increases collagen-1 and osteocalcin mRNA expression, stimulates alkaline phosphatase activity and enhances cell mineralization in osteoblast-like MC3T3-E1 cells (21). In addition, AMPK activation reportedly inhibits palmitate-induced apoptosis in osteoblasts (22). Furthermore, AMPK has been observed to stimulate osteoblast differentiation via induction of runt-related transcription factor 2 expression (23). Thus, these observations lead to the hypothesis that AMPK activation directs osteoblasts toward stimulating bone formation. $\mathrm{PGE}_{2}$ is a well-known autocrine/paracrine regulator of osteoblasts and acts as an important mediator of bone remodeling (10). By contrast, OPG, which prevents the biological effects of RANKL as a decoy receptor, negatively regulates RANKL-mediated osteoclastic bone resorption (7). Therefore, the results of the present study indicate that $\mathrm{PGE}_{2}$-activated AMPK in osteoblasts functions as a modulator of bone metabolism via OPG synthesis, resulting in the upregulation of bone formation, and these results may provide a novel insight into bone metabolism. Further investigation would be necessary to clarify the exact roles of AMPK in bone metabolism.

The results of the current study indicate that AMPK functions as a positive regulator in $\mathrm{PGE}_{2}$-stimulated $\mathrm{OPG}$ synthesis via $\mathrm{SAPK} / \mathrm{JNK}$ activation in osteoblasts.

\section{Acknowledgements}

The authors would like to thank Mrs. Yumiko Kurokawa for her technical assistance. The current study was supported in part by the Grant-in-Aid for Scientific Research from the Ministry of Education, Science, Sports and Culture of Japan (grant no. 19591042) and the Research Funding for Longevity Sciences from the National Center for Geriatrics and Gerontology, Japan (grant nos. 23-9 and 25-4).

\section{References}

1. Fogarty S and Hardie DG: Development of protein kinase activators: AMPK as a target in metabolic disorders and cancer. Biochim Biophys Acta 1804: 581-591, 2010.

2. Mihaylova MM and Shaw RJ: The AMPK signalling pathway coordinates cell growth, autophagy and metabolism. Nat Cell Biol 13: 1016-1023, 2011.

3. Rutter GA and Leclerc I: The AMP-regulated kinase family: Enigmatic targets for diabetes therapy. Mol Cell Endocrinol 297: 41-49, 2009.

4. Karsenty G and Wagner EF: Reaching a genetic and molecular understanding of skeletal development. Dev Cell 2: 389-406, 2002.

5. Shah M, Kola B, Bataveljic A, Arnett TR, Viollet B, Saxon L, Korbonits $\mathrm{M}$ and Chenu C: AMP-activated protein kinase (AMPK) activation regulates in vitro bone formation and bone mass. Bone 47: 309-319, 2010.

6. Kato K, Tokuda H, Adachi S, Matsushima-Nishiwaki R, Natsume H, Yamakawa K, Gu Y, Otsuka T and Kozawa O: AMP-activated protein kinase positively regulates FGF-2-stimulated VEGF synthesis in osteoblasts. Biochem Biophys Res Commun 400: 123-127, 2010.

7. Simonet WS, Lacey DL, Dunstan CR, Kelley M, Chang MS, Lüthy R, Nguyen HQ, Wooden S, Bennett L, Boone T, et al: Osteoprotegerin: A novel secreted protein involved in the regulation of bone density. Cell 89: 309-319, 1997.

8. Kong YY, Yoshida H, Sarosi I, Tan HL, Timms E, Capparelli C, Morony S, Oliveira-dos-Santos AJ, Van G, Itie A, et al: OPGL is a key regulator of osteoclastogenesis, lymphocyte development and lymph-node organogenesis. Nature 397: 315-323, 1999.

9. Theoleyre S, Wittrant Y, Tat SK, Fortun Y, Redini F and Heymann D: The molecular triad OPG/RANK/RANKL: Involvement in the orchestration of pathophysiological bone remodeling. Cytokine Growth Factor Rev 15: 457-475, 2004.

10. Hikiji H, Takato T, Shimizu T and Ishii S: The roles of prostanoids, leukotrienes and platelet-activating factor in bone metabolism and disease. Prog Lipid Res 47: 107-126, 2008.

11. Zhu Z, Fu C, Li X, Song Y, Li C, Zou M, Guan Y and Zhu Y: Prostaglandin $\mathrm{E}_{2}$ promotes endothelial differentiation from bone marrow-derived cells through AMPK activation. PloS One 6: e23554, 2011.

12. Yamamoto $\mathrm{N}$, Tokuda $\mathrm{H}$, Kuroyanagi $\mathrm{G}$, Mizutani $\mathrm{J}$, Matsushima-Nishiwaki R, Kondo A, Kozawa $\mathrm{O}$ and Otsuka T: Regulation by resveratrol of prostaglandin $\mathrm{E}_{2}$-stimulated osteoprotegerin synthesis in osteoblasts. Int J Mol Med 34: 1439-1445, 2014.

13. Sudo H, Kodama HA, Amagai Y, Yamamoto S and Kasai S: In vitro differentiation and calcification in a new clonal osteogenic cell line derived from newborn mouse calvaria. J Cell Biol 96: 191-198, 1983.

14. Kozawa O, Tokuda H, Miwa M, Kotoyori J and Oiso Y: Cross-talk regulation between cyclic AMP production and phosphoinositide hydrolysis induced by prostaglandin $\mathrm{E}_{2}$ in osteoblast-like cells. Exp Cell Res 198: 130-134, 1992. 
15. Laemmli UK: Cleavage of structural proteins during the assembly of the head of bacteriophage T4. Nature 227: 680-685, 1970.

16. Kato $\mathrm{K}$, Ito $\mathrm{H}$, Hasegawa $\mathrm{K}$, Inaguma $\mathrm{Y}$, Kozawa $\mathrm{O}$ and Asano T: Modulation of the stress-induced synthesis of hsp27 and alpha B-crystallin by cyclic AMP in C6 rat glioma cells. J Neurochem 66: 946-950, 1996.

17. Hawley SA, Davison M, Woods A, Davies SP, Beri RK, Carling D and Hardie DG: Characterization of the AMP-activated protein kinase kinase from rat liver and identification of threonine 172 as the major site at which it phosphorylates AMP-activated protein kinase. J Biol Chem 271: 27879-27887, 1996.

18. Zhou G, Myers R, Li Y, Chen Y, Shen X, Fenyk-Melody J, Wu M, Ventre J, Doebber T, Fujii N, et al: Role of AMP-activated protein kinase in mechanism of metformin action. J Clin Invest 108: 1167-1174, 2001.

19. Kyriakis JM and Avruch J: Mammalian mitogen-activated protein kinase signal transduction pathways activated by stress and inflammation. Physiol Rev 81: 807-869, 2001.
20. Widmann C, Gibson S, Jarpe MB and Johnson GL: Mitogen-activated protein kinase: Conservation of a three-kinase module from yeast to human. Physiol Rev 79: 143-180, 1999.

21. Kanazawa I, Yamaguchi $T$, Yano S, Yamauchi $M$ and Sugimoto T: Metformin enhances the differentiation and mineralization of osteoblastic MC3T3-E1 cells via AMP kinase activation as well as eNOS and BMP-2 expression. Biochem Biophys Res Commun 375: 414-419, 2008.

22. Kim JE, Ahn MW, Baek SH, Lee IK, Kim YW, Kim JY, Dan JM and Park SY: AMPK activator, AICAR, inhibits palmitate-induced apoptosis in osteoblast. Bone 43: 394-404, 2008.

23. Jang WG, Kim EJ, Lee KN, Son HJ and Koh JT: AMP-activated protein kinase (AMPK) positively regulates osteoblast differentiation via induction of Dlx5-dependent Runx2 expression in MC3T3E1 cells. Biochem Biophys Res Commun 404: 1004-1009, 2011 